\title{
La construcción informativa de México en la prensa española de referencia: La Vanguardia, El País y El Mundo
}

\author{
The informative construction of Mexico in the Spanish press of reference: \\ La Vanguardia, El País \& El Mundo
}

\author{
Dr. José Ramón Santillán Buelna \\ Universidad Rey Juan Carlos | Camino del molino s/n. 28943. Fuenlabrada. Madrid | España | \\ http://orcid.org/0000-0002-0946-9564 | joseramon.santillan@urjc.es
}

\section{Dr. Alberto Zuart Garduño}

Universidad Autónoma de Chiapas | Boulevard Belisario Domínguez, Km. 1081, s/n. 29050

Tuxtla Gutiérrez. Chiapas | México | https://orcid.org/0000-0003-4915-1566 |

alberto.zuart@unach.mx

\section{Fechas | Recepción: 27/05/2021 | Aceptación: 05/08/2021}

\section{Resumen}

El presente artículo constituye un estudio sobre la construcción informativa en la prensa española de las relaciones entre España y México en los últimos años, desde la perspectiva de la Agenda setting. El objetivo principal de la investigación es comprender la imagen que de México presentan tres diarios españoles de referencia internacional. Para ello, se llevó a cabo un análisis de contenido a un total de 620 noticias de periódicos como $L a$ Vanguardia, El País y El Mundo, publicadas durante el año 2019, con la finalidad de determinar, entre otros aspectos, ciclos informativos, el lugar dónde ocurren los hechos, quienes firman las noticias, las temáticas tratadas, los protagonistas y los enfoques informativos. Entre los principales resultados encontrados se destaca que, emblemáticamente cinco de cada diez noticias aparecen publicadas en el rotativo de El País, además los corresponsales son los que firman el mayor número de informaciones vertidas y la Ciudad de México se enfatiza como el epicentro informativo. Derivado de la investigación, también se encontró que existe

\begin{abstract}
This article constitutes a study on the informative construction in the Spanish press of the relations between Spain and Mexico in recent years from the Agenda Setting perspective. The main objective of the research is to understand the image of Mexico presented by three Spanish newspapers of international reference. To achieve this, a content analysis was carried out on a total of 620 news items from newspapers such as La Vanguardia, El País and El Mundo, published during 2019, to determine, among other aspects: news cycles, the place where the events occur, who signs the news, the topics covered, the protagonists, and the informative approaches. Among the main results found, it stands out that, emblematically, five out of ten news items are published in the newspaper EI País; in addition, correspondents are the ones who sign the largest number of information released, and Mexico City is emphasized as the news epicenter. Tt was also found that there is a broad predominance of domestic policy issues over foreign ones, as well as economic and cultural issues, and the image that
\end{abstract}


un predominio amplio de las temáticas de política interna por encima de las de política exterior, así como de los asuntos económicos y culturales, y la imagen que permea de forma recurrente en los diarios y proyectan es la de un país peligroso, económicamente atractivo, culturalmente sólido y como un lugar histórico de asilo.

Palabras clave: agenda setting, prensa española, imagen mediática, México, España. permeates recurrently in newspapers and projects is that of a dangerous country, economically attractive, culturally solid, and as a historic place of asylum.

Keywords: agenda setting, spanish press, media image, Mexico, Spain.

\section{INTRODUCCIÓN}

A partir de la perspectiva de los efectos cognitivos de los medios de comunicación, que además desempeñan un papel fundamental en la percepción de la realidad que tienen sus audiencias (Saperas, 1987; Shütz, 1995; Schütz y Luhmann, 2003), y concretamente desde el análisis de la agenda temática ${ }^{1}$ (McCombs y Shaw, 1972; McCombs, 2005), este artículo presenta un estudio acerca de la construcción informativa que llevan a cabo de México tres diarios españoles, con el fin de comprender la imagen que proyectan del país azteca.

En este sentido, el análisis del proceso informativo que la prensa extranjera dedica a una nación determinada, esto es, como factor que afecta positiva o negativamente su percepción internacional, destaca como uno de los aspectos importantes del estudio de la imagen país en el ámbito de los tratados de comunicación. Es decir, en relación con su papel como fuente sustancial para proveer datos sobre una nación a audiencias foráneas. En este caso, a través de las noticias, acerca al público con asuntos y actores que se desarrollan en otros países, además proporciona elementos para conocerlos y valorarlos (Bartolezzi, 1996; Tulloch, 2004).

En este escenario, la prensa y los periodistas como mediadores seleccionan y remarcan determinados aspectos de un territorio y omiten otros. Estos proponen "una agenda de asuntos públicos internacionales", un espacio de conocimiento, así como de debate de las temáticas políticas, económicas, culturales y sociales de esa nación en el exterior (Santillán, 2017, p. 20; Acosta, 2006). Todo ello, configura la imagen país, una representación pública internacional, que también estará condicionada por el enfoque y tratamiento de las noticias que hagan los medios de dicha región.

En consecuencia, este trabajo abordó el estudio del proceso informativo que México, nación de estrechos lazos históricos con España, recibe en las noticias que publican tres diarios de alcance internacional, como son: La Vanguardia, El País y El Mundo. Para efectos de este tratado, se empleó la técnica del análisis de contenido cuantitativo, dado que se buscó identificar la construcción periodística y llevar a cabo la comprensión de la imagen que del país mexicano proyectan los tres medios españoles.

Los objetivos de esta investigación son los siguientes:

A. Cuantificar el número total de noticias que se publican, y por cada uno de los periódicos.

\footnotetext{
${ }^{1}$ En este trabajo se utilizará: agenda informativa, agenda temática o agenda setting, de manera indistinta, para referirnos al conjunto de temas presentes en los media en un período determinado.
} 
B. Identificar los ciclos informativos.

C. Evaluar la relevancia de las noticias, medidas en número de palabras, fotografías e ilustraciones.

D. Determinar el lugar en donde ocurren las noticias.

E. Identificar la agenda temática en los diarios en relación con México.

F. Registrar a los actores políticos y sociales que protagonizan las noticias.

G. Evaluar los contenidos periodísticos para conocer cómo pueden afectar positiva o negativamente a la imagen de México.

\section{APROXIMACIÓN A LOS CONCEPTOS DE AGENDA SETTING Y TEORÍA DEL ENCUADRE}

El origen de la Agenda setting reside en que los medios de comunicación tienen el poder de elegir los asuntos que pueden ser percibidos por la opinión pública como importantes, parte de un análisis de la relación entre medios y audiencias. En otras palabras, en la lógica de la Agenda setting, los medios de comunicación "establecen no qué ni cómo la gente debe pensar, sino aquellos temas en torno a los cuales pensar, discutir y formarse una opinión" (Cohen, 1963; McCombs y Shaw, 1972, Aruguete, 2016).

En este sentido, el campo de la sociología interpretativa ofrece una serie de razonamientos que dan vida a la teoría denominada como teoría del encuadre, de los marcos o del framing. Ésta última concepción surgió en el espacio psicológico, a través de la obra de Erving Goffman, quien incorporó los elementos sociológicos. Más tarde, esta noción resultará importante en el estudio de los medios de comunicación. Los frames de Goffman pueden ser entendidos como configuraciones socializadas por los grupos sociales, a través de las cuales se mira y se hace propia la realidad; en este contexto los medios de comunicación se perciben como mediadores influyentes en la construcción de encuadres del discurso social, dado que no reflejan una realidad de forma pasiva, sino que son parte de una realidad social a la que construyen con sus propios marcos (Bennet, 1996).

Siguiendo a Sebastián de Erice (1994), podría afirmarse que la sociología interpretativa ejercita el entendimiento para alcanzar a comprender las significaciones de la realidad para cada ser humano, esto ocurre mediante un proceso interpretativo en el que cobra un papel importante la interacción y en el que la teoría del framing se ofrecerá como la herramienta que permitirá describir dicho proceso de interpretación y de significaciones particulares. Será, en palabras Sádaba Garraza (2001) "una herramienta concreta que manejen los sociólogos para acceder a los significados de la realidad".

No obstante, en el proceso de construcción informativa es posible percibir determinadas cualidades que distinguen a las hipótesis que dan vida a las teorías de Agenda setting y framing. Mientras que la Agenda setting se ocupa de estudiar la importancia o significación de temas $u$ objetos, la teoría del framing analizará los atributos que se le otorgan a dichos temas (Sheufele, 2000). Sin embargo, existen atributos en dos vertientes, la primera atiende la dimensión descriptiva y la segunda, a aquellos que su principal motivación será generar o influir en acciones de los receptores. Dicho de otro modo, hay atributos que constituyen el mensaje y hay otros que "definen un tema o idea central" buscando generar una acción en él o los receptores (McCombs y Ghanem, 2001). 
Para estar en posibilidades de analizar los atributos o frames, Ghanem (2009) propone cuatro dimensiones de estudio:

1. El asunto de una noticia

2. La presentación (tamaño y ubicación)

3. Los atributos cognitivos (detalles de aquello que es incluido en el frame)

4. Los atributos afectivos (los matices)

Estos cuatro aspectos de los atributos, se constituyen en la base a partir de la cual llevar a cabo una serie de comparaciones entre distintas agendas y, por supuesto, acompañan el desarrollo de esta investigación.

\section{PRENSA E IMAGEN-PAÍS}

La indagación del papel que desempeña la prensa, al mismo tiempo uno de los componentes capitales que inciden en la representación que se proyecta de una nación a partir de los medios de comunicación, es un contenido de examen notorio en el ámbito de la investigación comunicativa, en relación con la imagen-país y la diplomacia pública (Dinnie, 2008; Xifra y San Eugenio, 2014). Algunos trabajos consideran que el conocimiento y valoración de una región en particular, puede intervenir en beneficio o en detrimento, en función del manejo y óptica de las noticias que publiquen los diarios internacionales (Noya, 2007; Santillán, 2017). Otras investigaciones aseguran que, en el desarrollo de la actividad diplomática de una nación, el uso de los medios de comunicación facilita la instrumentalización de la política exterior y mejora su percepción mundial (Azpiroz, 2013; Villanueva, 2012; Nieto, Peña y Hoffman, 2002; Neuman, 1996). Según estas aportaciones, los medios de comunicación, incluida la prensa, son actores clave para la diplomacia pública por su papel como transmisores de mensajes, iconografías y valores, que configuran la imagen exterior de un país en un contexto internacional.

En este orden de ideas, una de las razones que explican la importancia de la prensa como definidora de la imagen-país, está en su papel de proveer a las audiencias, informaciones de acontecimientos internacionales que quedan fuera de la experiencia personal de la mayor parte de la población (Mc Combs, 2006, p. 23) y que fijan la agenda setting o agenda temática (Dearing y Elder, 1992; Mc Combs, y Shaw, 1972). Esta idea subraya su función de definir un catálogo de temas de un determinado país que seleccionan, jerarquizan e interpretan; contribuyendo con ello, tanto a la forma de cómo es conocido, además de cómo es valorado en el extranjero. Así, a partir de la cobertura, por ejemplo, cantidad y espacio de las noticias, autoría, fuentes, temáticas tratadas, protagonistas informativos, los diarios difunden referencias de los países. Esto es, se convierten en definidores de la imagen de un país en la opinión pública internacional. Además, como ya se ha señalado, el punto de vista y el manejo que el conjunto de las publicaciones lleve a cabo de esa nación impactará en su autoridad o en menoscabo de su apreciación (Soto y Sánchez, 2016, p. 2).

Por ello, la agenda setting es un instrumento adecuado para investigar la relación entre la prensa y la configuración de la imagen-país. Sus conceptos teóricos y tradición metodológica permiten identificar la cobertura, temáticas, actores, enfoques y tratamientos informativos, de las noticias de un país que se generan en la prensa internacional. Entre los trabajos que corroboran esta idea se encuentran los de Want, Golan, y Lee (2004), quienes han estudiado la cobertura 
periodística de los países extranjeros en la prensa estadunidense, demostrando la influencia entre representación mediática y percepción pública. Por su parte, Urdaneta (2011) concluye que cuatro diarios españoles, El País, El Mundo, ABC y La Vanguardia, hicieron un tratamiento negativo de las noticias de Venezuela, lo que generó una imagen-país desfavorable para éste.

Por otra parte, las investigaciones del Instituto El Cano, think tank español, en relación con la imagen de España en el mundo, utilizan el enfoque teórico de la agenda setting para medir y valorar la presencia del país Ibérico en la prensa internacional. En forma paralela, los tratados que podemos citar están los de González, Martínez y Sánchez (2012); así como, los de Soto y Sánchez (2016), cuyos resultados muestran que la imagen de España está condicionada por el tratamiento de las noticias que los medios de comunicación internacionales conciban de ella.

En cuanto a las observaciones realizadas con respecto al estudio de la imagen de México en España, los resultados señalan que en los últimos diez años en la prensa local prevalece un tratamiento marcadamente negativo, producto de la gran cantidad de noticias que se publican sobre la violencia en el país, vinculada principalmente con el narcotráfico (Miranda e Iglesias, 2015; Gabino, 2012; Urriza, 2012). Otros estudios concluyen que las informaciones valoradas positivamente, como es el caso de la economía o la cultura, tienen poca proyección mediática, que no logran redimensionar la imagen de México como un país con grandes oportunidades económicas, un sólido softpower y una diáspora cualificada y talentosa que refleje otras caras del país (Curzio, 2017; Santillán y Del Orbe, 2020; Santillán, 2018).

\section{METOdOlOGÍA}

Existen diversos análisis que han abordado el fenómeno de imagen país a partir de una perspectiva cualitativa, entre ellos se destaca el trabajo de Villanueva (2012), quien ha señalado que países como Brasil, Argentina y España, los dos primeros con mayor atención y el último en menor grado, pretenderían construir una imagen de México negativa en un contexto globalizado para ganar los mercados de inversiones, el turismo, la diplomacia multilateral y, por supuesto, el liderazgo simbólico ante las demás naciones al buscar ser líderes regionales y mundiales como potencias emergentes.

En este sentido, para contribuir a las discusiones de estos temas y enriquecerlos, la metodología empleada en este estudio fue un análisis de contenido cuantitativo (Igartua, 2006; Wimmer y Dominick, 1997; Krippendorf, 1990). Dicho método permite medir de forma sistemática y objetiva los contenidos comunicativos, en este caso las noticias sobre México publicadas en tres diarios españoles. Los medios seleccionados son de información general y de referencia, caracterizados por una estructura organizativa, controles de calidad y una agenda informativa global, que tiene impacto e influencia en las élites políticas, económicas y culturales (Merrill, 1968; Beneyto e Imbert, 1986).

Cabe destacar también que, son los tres medios de prensa más leídos, tanto en su versión de papel como en su alojamiento web. La Asociación para la Investigación de Medios de Comunicación (AIMC), a través del Estudio General de Medios (2019)², apuntaba que tenían las siguientes cifras de lectores: La Vanguardia (549.000); El País (1.013.00); El Mundo (671.000).

\footnotetext{
${ }^{2}$ Asociación para la Investigación de Medios de Comunicación (AIMC) (2019). Estudio General de Medios. Recuperado de http://aimc.es.
} 
Además, en su versión online sus usuarios únicos eran, en millones, lavanguardia.com $(19,1)$, elpais.com $(20,9)$, elmundo.es $(21)^{3}$.

La muestra analizada comprende un número de 620 noticias publicadas sobre México en estos tres periódicos en su edición digital, del 1 de enero hasta el 31 de diciembre de 2019. Las informaciones se obtuvieron a través de un muestreo aleatorio, se seleccionaron dos semanas de cada mes para los diarios. El procedimiento de recopilación se basó en búsquedas selectivas, a través de meta-buscadores para la recuperación de las noticias en formato "pdf".

La unidad de análisis escogida es la noticia, y la definimos como pieza que hace referencia a acontecimientos de actualidad, en donde México o los mexicanos son los protagonistas principales de la información. Excluimos crónicas, entrevistas, reportajes, artículos de opinión, editoriales, columnas, porque estudios previos han concluido que son las noticias las que predominan en la cobertura periodística de México en España (Santillán, 2017).

El protocolo de análisis de contenido 4 está formado por tres bloques. El primero ha permitido reconocer la cantidad de noticias en cada diario, así como la fecha de publicación, además de la relevancia informativa de cada pieza y el lugar donde ocurre el acontecimiento que se informa. El segundo apartado se ha ocupado de los temas de las notas periodísticas, catalogados en cuatro áreas: política nacional, política exterior, economía, y cultura. Después, se definieron 20 categorías que clasificaban el tema concreto. Por ejemplo, para el área de política nacional había once ítems. También en este conjunto identificamos a los protagonistas de la información, a partir de 20 categorías, que incluían a personajes de los diferentes ámbitos sociales (política, economía, cultura, sociedad).

Posteriormente, el tercer bloque examina el tratamiento de la información -en valores de neutro, positivo y negativo- y sus efectos para la imagen de México; es decir, primero de forma global y después en cuatro dimensiones: política nacional, económica, política exterior y cultura.

Para determinar la fiabilidad del análisis de contenido, se escogió una muestra aleatoria de 50 noticias (20 El País, 15 La Vanguardia y 15 El Mundo); además, para comprobar el grado de fiabilidad de la codificación y usando la fórmula de "Holsti" se obtuvieron valores superiores al 85 por ciento, de acuerdo en las principales variables.

Por último, para el tratamiento e interpretación de los datos utilizamos el programa Statiscal Package for the Social Sciences (SPSS). Esta herramienta informática nos sirvió para generar un análisis estadístico detallado y riguroso, de tal manera que, permitió ofrecer porcentajes, análisis bivarial y gráficos, para examinar la cobertura de México en La Vanguardia, El País y El Mundo y sus efectos para la imagen internacional del país.

\section{ANÁLISIS}

\subsection{En un año, 620 noticias}

Por lo que se refiere al análisis, como se observa en la tabla 1, se indica que en el año de 2019 se publicaron 620 noticias sobre México en los tres periódicos españoles seleccionados. Las más

\footnotetext{
${ }^{3}$ Comscore (2019). Recuperado de https://www.comscore.com/esl.

${ }^{4}$ El protocolo de análisis de contenido fue elaborado por el equipo de investigadores del Observatorio de México en España, mismo que se ha aplicado en numerosos estudios sobre las relaciones entre prensa internacional e imagen país (Santillán, 2017; Del Orbe-Ayala, 2018; Santillán y Acosta, 2019).
} 
numerosas se encuentran en El País (EP) con 320 (51,6 \%), seguido de La Vanguardia (LV), que arroja 175 (28,2 \%) y, por último, El Mundo (EM) presenta 125 (20,2\%).

Por tanto, la mayor producción informativa la concentra El País; de cada 10 noticias difundidas sobre México, cinco son editadas por este diario. Cabe resaltar que cuenta con más recursos, así como una oficina en la Ciudad de México; ésta se conforma por una Redacción de 20 periodistas, que se dedican a cubrir en exclusiva la actualidad del país y coordinar la Edición América ${ }^{5}$. Este hecho ha de tenerse en cuenta a la hora de interpretar los datos del presente estudio.

El punto anterior también es importante, dado que El País será el diario que tendrá mayor influencia e impacto a nivel internacional -sobre todo en el mundo donde se habla españolpara transmitir imágenes, ideas y percepciones de México.

Tabla 1

Noticias por diario

\begin{tabular}{|l|c|c|}
\hline \multicolumn{1}{|c|}{ Diario } & Frecuencia & Porcentaje \\
\hline La Vanguardia (LV) & 175 & $28,2 \%$ \\
\hline El País (EP) & 320 & $51,6 \%$ \\
\hline El Mundo (EM) & 125 & $20,2 \%$ \\
\hline Total & 620 & $100 \%$ \\
\hline
\end{tabular}

Fuente: elaboración propia.

\subsection{Ciclos informativos}

Con respecto a la observación de media, se publicaron 51,6 noticias mensuales. Como se expresa en la tabla 2, podemos observar cómo la cobertura sobre México muestra tres momentos. El primero, en los meses de enero y febrero se da la mayor atención informativa con 96 y 104 noticias; el segundo instante, ocurre los meses de julio, agosto y septiembre, cuando menos noticias se publican: 34,26 y 29, respectivamente. Y por último, para el resto de los meses hay pocas diferencias en la cantidad de textos que se publican.

\footnotetext{
${ }^{5}$ La Redacción de El País en la Ciudad de México, es la mayor del diario en el Continente Americano y acoge también la mesa digital desde la que se coordina la Edición América. El País (2019). El País refuerza su apuesta por América. Recuperado de https://elpais.com/internacional/2019/11/27/mexico/1574821202_380040.html.
} 
Tabla 2

Noticias por mes y diario

\begin{tabular}{|c|c|c|c|c|}
\hline Mes & LV & EP & EM & Total \\
\hline Enero & 21 & 55 & 20 & 96 \\
\hline Febrero & 45 & 42 & 17 & 104 \\
\hline Marzo & 23 & 22 & 7 & 52 \\
\hline Abril & 11 & 17 & 12 & 40 \\
\hline Mayo & 14 & 27 & 5 & 46 \\
\hline Junio & 9 & 22 & 20 & 51 \\
\hline Julio & 9 & 19 & 6 & 34 \\
\hline Agosto & 3 & 20 & 3 & 26 \\
\hline Septiembre & 7 & 18 & 4 & 29 \\
\hline Octubre & 11 & 21 & 13 & 45 \\
\hline Noviembre & 10 & 33 & 9 & 52 \\
\hline Diciembre & 12 & 24 & 9 & 45 \\
\hline Total & 175 & 320 & 125 & 620 \\
\hline
\end{tabular}

Fuente: elaboración propia.

De igual modo, el pico de mayor cantidad de noticias, coincide con cuatro acontecimientos: a) El inicio de la presidencia de Andrés Manuel López Obrador, política que denomina la "Cuarta Transformación"6; b) El Óscar para Alfonso Cuarón por su película "Roma" (2018); c) La visita del presidente español Pedro Sánchez; y d) La caravana migrante de centroamericanos (en los meses de enero y febrero).

Mientras tanto, el momento de baja cobertura tuvo lugar en verano (julio, agosto y septiembre), que corresponde al período de vacaciones establecido y de baja actividad política. Con respecto a la producción mensual de noticias, se desarrolla en términos de "normalidad" informativa; es decir, de funcionamiento típico de las rutinas periodísticas, cuando hay asuntos que tienen interés se cubren, cuando baja la importancia, se da menos atención. Esta idea se verifica con observar que acontecimientos como la marcha feminista para protestar contra las desapariciones de mujeres (agosto); la captura fallida del hijo del Chapo Guzmán (octubre); o el

\footnotetext{
${ }^{6}$ Andrés Manuel López Obrador afirma que su presidencia es una época histórica en México, la llama la "Cuarta Transformación", después de los acontecimientos históricos como la Independencia del país de España, la Reforma liberal y la Revolución Mexicana.
} 
asesinato de la familia LeBaron, aparentemente vinculada al crimen organizado (noviembre); estos ejemplos tienen relevancia informativa porque afectan a tres áreas importantes de la gestión de política nacional: los derechos humanos, la lucha contra el narcotráfico y el combate a la violencia.

Por último, en la cobertura mensual identificamos "acontecimientos recurrentes" o "estacionales", que suceden cada año y que la prensa está acostumbrada a cubrir, como el aniversario del Exilio Republicano Español (cinco noticias en junio), la festividad de "El Grito" (alusivo a la Independencia de México), (seis noticias en septiembre); la celebración de "El Día de Muertos" (ocho noticias), y la Feria Internacional del Libro de Guadalajara (FIL) (12 noticias en noviembre).

\subsection{Relevancia informativa}

Por lo que se refiere a la relevancia de las informaciones internacionales publicadas en los diarios, ésta puede medirse en términos de espacio, fotografías y apoyo infográfico ilustraciones, esquemas- (Antovica, De Esteban, Gértrudix, 2014).

Con relación a estos factores, definimos tres valores: 1) Baja: notas de un máximo de 500 palabras y sin fotografía. 2) Media: entre 500 y 1000 palabras, con foto e ilustración; 3) Alta: más de 1000 palabras, fotografías e ilustraciones.

La Tabla 3 muestra que las noticias sobre México han tenido como dato principal una relevancia media del $46,3 \%$. Esto es, casi la mitad de las noticias ocuparon dos cuartos de página, fueron acompañadas de una fotografía y llevaron ilustración. Por lo que respecta al valor informativo de relevancia alta, éste concentra el $24,3 \%$. La suma de estos dos datos $(70,6 \%)$ nos habla de un interés informativo importante de los tres diarios en cuanto a espacio, fotografías e ilustraciones respecto del país azteca.

Tabla 3

Relevancia informativa en espacio, fotografías e ilustraciones

\begin{tabular}{|c|c|c|c|c|c|}
\hline Relevancia & LV & EP & EM & Frecuencia & $\%$ \\
\hline Baja & 116 (18,7 \%) & $\begin{array}{c}30 \\
(4,8 \%)\end{array}$ & $\begin{array}{c}38 \\
(6,1 \%)\end{array}$ & 184 & 29,7 \\
\hline Media & $\begin{array}{c}49 \\
(7,9 \%)\end{array}$ & $\begin{array}{c}177 \\
(28,5)\end{array}$ & $\begin{array}{c}61 \\
(9,8 \%)\end{array}$ & 287 & 46,3 \\
\hline Alta & $\begin{array}{c}10 \\
(1,6 \%)\end{array}$ & $\begin{array}{c}112 \\
(18,2)\end{array}$ & $\begin{array}{c}26 \\
(4,2 \%)\end{array}$ & 149 & 24,3 \\
\hline TOTAL & $\begin{array}{c}(175) \\
28,2 \%\end{array}$ & $\begin{array}{c}320 \\
(51,6 \%)\end{array}$ & 125 (20,2 \%) & 379 & 100,0 \\
\hline
\end{tabular}

Fuente: elaboración propia. 
Finalmente, la categoría baja relevancia, que tiene el valor más bajo con un $29,7 \%$ (184 noticias), indica que de cada 10 notas periodísticas publicadas, tres fueron menores de un cuarto de página y sin fotografía. Este dato menor, confirma un interés medio concedido por los dos diarios españoles en resaltar las noticias con imágenes para atraer la atención del lector en la cobertura informativa.

Dicho lo anterior, por periódicos, el análisis bivarial muestra que EI País destaca en la publicación de más noticias de relevancia media y alta (28,5\% y $18,2 \%)$. El Mundo oscila entre valores medios y bajos (9,8 \% y 4,2\%) y La Vanguardia es el diario que otorga menor relevancia informativa (18,8\%). Dicho de otro modo, el primer diario le otorga más espacio informativo y fotografías a la información sobre México. Este dato coincide con los ofrecidos en otros estudios sobre la cobertura del país latinoamericano en la prensa española donde se afirma que El País es el diario español que concede mayor importancia a la información internacional que la prensa regional (Santillán y Acosta, 2019; Santillán, 2017).

\subsection{La Ciudad de México, epicentro informativo}

Acorde con el análisis de las entidades como origen geográfico de los acontecimientos, aparecen 10 de las 32 entidades federativas en las que está organizado el país (véase tabla 4). Sobresale la Ciudad de México con el 70 \%. Después Jalisco $8 \%$; Chiapas presenta un 3 \%; el Estado de México y Chihuahua 2,7 \%, respectivamente; Sinaloa 2,5\%. Por último, Guerrero y Baja California 2,2 \%, con sendos porcentajes; y Oaxaca y Nuevo León con un 1,5\%.

Tabla 4

Estados donde ocurre la noticia

\begin{tabular}{|l|c|}
\hline \multicolumn{1}{|c|}{ Entidad federativa } & $\%$ \\
\hline Ciudad de México & $70 \%$ \\
\hline Jalisco & $8 \%$ \\
\hline Chiabas & $3 \%$ \\
\hline Estado de México & $2.7 \%$ \\
\hline Chihuahua & $2.7 \%$ \\
\hline Sinaloa & $2.5 \%$ \\
\hline Guerrero & $2.2 \%$ \\
\hline Baia California & $2.2 \%$ \\
\hline Oaxaca & $1.5 \%$ \\
\hline Nuevo León & $1.5 \%$ \\
\hline Otros & $3 \%$ \\
\hline Total & $100 \%$ \\
\hline
\end{tabular}

Fuente: elaboración propia

Como se señaló arriba, la sobrerrepresentación de la Ciudad de México, como origen geográfico de los acontecimientos, se debe a que es la capital del país y el principal centro político, económico, académico, cultural y de ocio. Por lo tanto, será el lugar dominante a partir del cual se generan la mayoría de las noticias. 
Asimismo, las menciones para estados como Jalisco, Sinaloa, Guerreo, Oaxaca, Chihuahua, Nuevo León, y Estado de México, suman el 18,4\% y se relacionan como sitios donde ocurren noticias vinculadas con la violencia, inseguridad y narcotráfico.

Además, las entidades de Baja California y Chiapas, que suman el 5,2\%, aparecen como lugares dónde se producen acontecimientos relacionados con los aspectos fronterizos de norte y sur. En el caso del primero, se trata de asuntos de migración y seguridad con los Estados Unidos. En contraste, para el segundo las directrices se concentran en la gestión de la frontera con Guatemala y el fenómeno social de la caravana migrante de centroamericanos que necesitan cruzar México para llegar a suelo estadunidense.

\section{5. Áreas y temáticas}

Avanzando en nuestro razonamiento, la tabla 5 señala que en el tema de las publicaciones, una vez organizadas por áreas, se destacan las noticias de asuntos relacionados con la política nacional con el $56,3 \%$. A continuación, figuran las de política exterior con $17,1 \%$; seguido de las de cultura con $13,7 \%$, y por último, economía/negocios arroja un $12,9 \%$.

Tabla 5

Áreas de las noticias por diario

\begin{tabular}{|c|c|c|c|}
\hline LV & EP & EM & TOTAL \\
\hline $14,5 \%$ & $32,9 \%$ & $8 \%$ & $56,3 \%$ \\
\hline $3,7 \%$ & $6 \%$ & $3,5 \%$ & $17,1 \%$ \\
\hline $5,6 \%$ & $6,5 \%$ & $5,5 \%$ & $13,7 \%$ \\
\hline $4,5 \%$ & $6,3 \%$ & $2,1 \%$ & $12,9 \%$ \\
\hline $28,3 \%$ & $51,7 \%$ & $20,1 \%$ & $100 \%$ \\
\hline
\end{tabular}

Fuente: elaboración propia.

En este sentido, como resultado, las cuestiones en relación con la gestión del gobierno mexicano de los problemas internos del país, que son arriba de la mitad de las noticias publicadas en los tres diarios, serán las que determinarán la imagen que se proyectará de México en la opinión pública española.

Consideremos lo descrito líneas arriba por cada periódico, aparece El País como el diario que más informaciones publica de cada una de las cuatro áreas temáticas. Sobresalen las de política nacional con el 32,9\%, que son más de la mitad de La Vanguardia que posee el 14,5 \% y tres veces por encima que $E I$ Mundo con su $8 \%$.

En particular, los tres diarios se caracterizan por tener como segunda área de tratamiento el rubro de la política exterior, en este marco generaron el $17,1 \%$ del total de noticias publicadas.

Otro punto es que en La Vanguardia, con 3,7 \%, y El Mundo, 3,5\%, se aprecian datos similares en la cantidad de noticias publicadas sobre asuntos de cultura y de política exterior (5,6 \% y 5,5 $\%$, respectivamente). Por lo que se refiere al área de economía/negocios, en el primer diario fueron más frecuentes con el $4,5 \%$; en cambio, en el segundo se obtuvo un $2,1 \%$. 
Ahora bien, el gráfico 1 presenta los temas más tratados en los tres diarios sobre México. Se observa que en política nacional, la violencia que impera en el país, con un $25 \%$ del total, fue el asunto que mayor interés informativo tuvo para la prensa. En segunda instancia, la gestión del presidente Andrés Manuel López Obrador (AMLO) con el $20 \%$; y por último, las noticias sobre los aspectos de la corrupción ocuparon el $9 \%$.

De manera análoga, en materia de economía, la agenda se centró en las inversiones extranjeras en México con el $11 \%$. Se trató de temas relacionados con empresas españolas como son: BBVA, Santander, Iberdrola, Gas Natural. En política exterior, destacó el tema de la relación con Estados Unidos con el 9 \% y tuvo como referente la construcción del muro, así como la amenaza de poner aranceles a productos mexicanos, además de la aprobación del Tratado de Comercio con Estados Unidos y Canadá (T-MEC). En cuanto a la relación con España ocupó el 7 \%, concentrándose en los pormenores sobre la carta de López Obrador al rey Felipe VI de España para pedir una disculpa española por los abusos cometidos contra los indígenas durante la Conquista-, aunado a la visita del presidente español Pedro Sánchez.

Por otra parte, en relación con el aspecto de cultura, Alfonso Cuarón y su película "Roma" (estrenada en 2018) que ganó tres Óscars, entre ellos, la categoría denominada: Mejor director; De igual forma, el premio "Goya" en España, como Mejor película Iberoamericana, centró toda la atención periodística. También hubo menciones para la Feria Internacional del Libro de Guadalajara (FIL). De esta manera se tuvo que el $8 \%$ de las informaciones fueron de cine y literatura.

\section{Gráfico 1}

Temáticas principales de la agenda periodistica

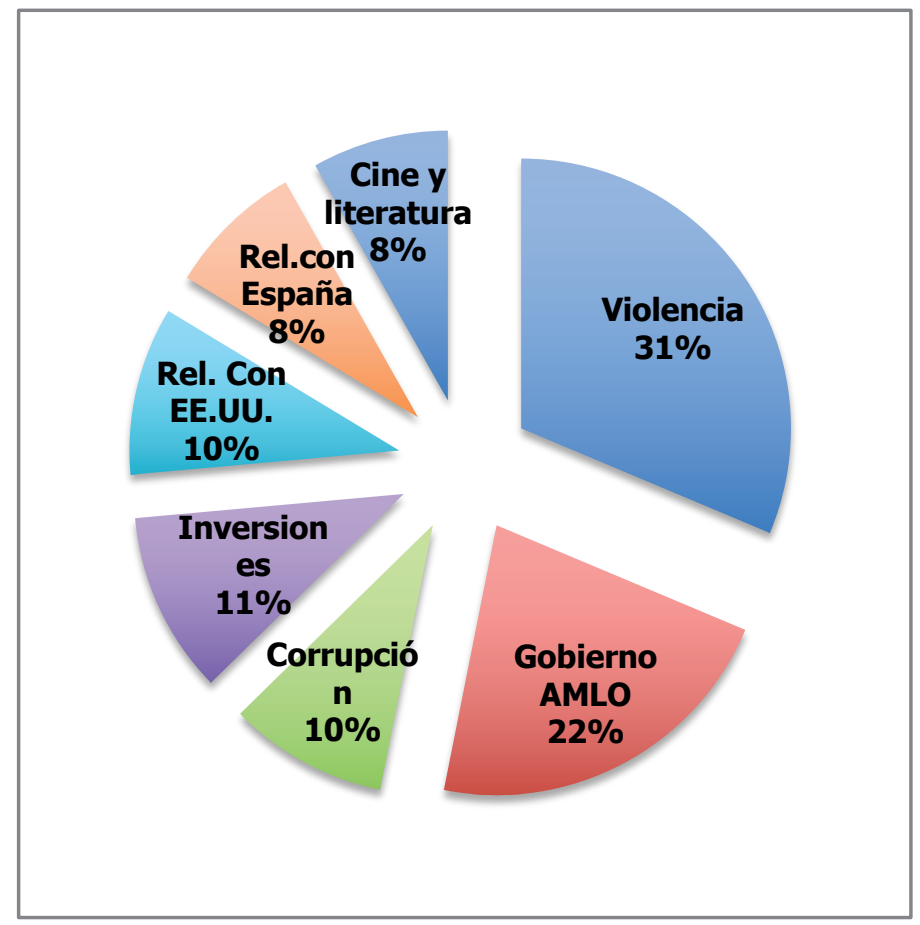

Fuente: elaboración propia.

Considerando que el resultado final, el predomino de la política nacional en la agenda periodística, sobre la base de temáticas como la violencia en el país, la gestión del presidente Andrés Manuel López Obrador y la corrupción, por delante de noticias acerca de la relación con 
Estados Unidos o España (política exterior), las inversiones extranjeras (economía/negocios) o el reconocimiento internacional a los cineastas y escritores (culturales), adquieren mayor importancia en la definición de la imagen internacional de México que se proyecta desde la prensa.

\subsection{Protagonistas}

El presidente Manuel Andrés López Obrador protagoniza el 20,6 \% de las noticias, los funcionarios públicos el 11,6 \%, las víctimas de delitos el 11,2 \%, integrantes de los partidos políticos el $8 \%$ y los grupos criminales (miembros del narcotráfico y crimen organizado) el 6,9\% (tabla 6). La relevancia de estos cinco actores va en sintonía con el predominio de los asuntos de política interna en la agenda informativa, donde la administración del presidente mexicano es la encargada de resolver problemas como la violencia, inseguridad y narcotráfico en el país.

Otros actores informativos son: el presidente estadounidense Donald Trump 6,1 \%, los migrantes centroamericanos 4,6\%, cineastas y escritores 3,7\% (sobresalen los nombres de Alfonso Cuarón y Guillermo del Toro), los periodistas 3,4 \% y las empresas y empresarios mexicanos 2,9\%, aparece Pemex e inversores como Carlos Slim, Allen Sanginés-Krause y Carlos Fernández.

Tabla 6

Protagonistas informativos

\begin{tabular}{|c|c|}
\hline Protagonistas & $\%$ \\
\hline Andrés Manuel López Obrador (presidente mexicano) & $20,6 \%$ \\
\hline Funcionarios & $11,6 \%$ \\
\hline Víctimas de delito & $11,2 \%$ \\
\hline Integrantes de partidos políticos & $8 \%$ \\
\hline Miembros de grupos criminales & $6,9 \%$ \\
\hline Donald Trump & $6,1 \%$ \\
\hline Migrantes centroamericanos & $4,6 \%$ \\
\hline Mexicanos residentes en España & $4 \%$ \\
\hline Empresas españolas & $4 \%$ \\
\hline Escritores/cineastas mexicanos & $3,7 \%$ \\
\hline Periodistas & $3,4 \%$ \\
\hline Empresas mexicanas & $2,9 \%$ \\
\hline El Chapo Gúzman & $2,7 \%$ \\
\hline Pedro Sánchez (presidente español) & $2,7 \%$ \\
\hline ONGs & $1,7 \%$ \\
\hline Activistas & $1,6 \%$ \\
\hline Académicos & $1,3 \%$ \\
\hline
\end{tabular}




\begin{tabular}{|l|c|}
\hline Otros & $2,4 \%$ \\
\hline Total & $100 \%$ \\
\hline
\end{tabular}

Fuente: elaboración propia.

El dato correspondiente del 2,7 \% para Joaquín "El Chapo" Guzmán, se debe por el interés que despertó en la prensa por su juicio en Nueva York y posterior condena a cadena perpetua por narcotráfico.

Los mexicanos residentes en España ocupan el 4\% y aparecen académicos, microempresarios, artistas y escritores como Jordi Soler y Juan Pablo Villalobos, que viven y publican activamente en Barcelona. También tienen protagonismo instituciones como la Casa de México, el Fondo de Cultura Económica y Asociaciones de mexicanos, como la Asociación Cultural Mexicano Catalana (CatMex).

Las empresas españolas BBVA, Santander, Iberdrola, Gas Natural tienen el $4 \%$ como actores informativos y el presidente Pedro Sánchez el 2,7 \%.

\subsection{Valoración de la noticia para la imagen de México}

En los resultados de la tabla 7, podemos observar que las noticias con valoración negativa para la imagen de México, son las que mayor presencia han tenido en los tres diarios españoles, de este modo se tiene el 47,5\%. Esto se complementó con el resultado de las positivas, el 35,8 \%; en tanto que las neutras representaron el $16,7 \%$.

Consideramos ahora, en la cobertura periodística de México primaron las connotaciones desfavorables, es decir, noticias que sus posibles consecuencias podían considerarse como no deseables para la imagen de México, de sus instituciones, así como responsables políticos o ciudadanos. 
Tabla 7

Valoración de las noticias por áreas y temáticas

\begin{tabular}{|c|c|c|c|c|}
\hline Área & Positiva & Neutra & Negativa & Total \\
\hline Política nacional & $8,5 \%$ & $8,3 \%$ & $39,4 \%$ & $56,2 \%$ \\
\hline Violencia & $3 \%$ & $2 \%$ & $20 \%$ & $25 \%$ \\
\hline Gestión AMLO & $4 \%$ & $1 \%$ & $15 \%$ & $20 \%$ \\
\hline Corrupción & $2,5 \%$ & $2 \%$ & $4 \%$ & $8,5 \%$ \\
\hline Política exterior & $6,6 \%$ & $6 \%$ & $4,1 \%$ & $16,6 \%$ \\
\hline Rel. con EEUU & $4 \%$ & $1 \%$ & $1 \%$ & $6 \%$ \\
\hline Rel. Con España & $1 \%$ & $1 \%$ & $4 \%$ & $6 \%$ \\
\hline Economía & $9,8 \%$ & , 7\% & $2,5 \%$ & $13 \%$ \\
\hline Inversiones & $8 \%$ & $1 \%$ & $1 \%$ & $10 \%$ \\
\hline Cultura & $10,8 \%$ & $1,1 \%$ & $1,6 \%$ & $13,5 \%$ \\
\hline $\begin{array}{l}\text { Reconocimiento a } \\
\text { cineastas/escritor } \\
\text { es }\end{array}$ & 9 & 0 & 0 & 9 \\
\hline Otros & $0,3 \%$ & $0,1 \%$ & $0,2 \%$ & $0,7 \%$ \\
\hline TOTAL & $35,8 \%$ & $16,7 \%$ & $47,5 \%$ & $100 \%$ \\
\hline
\end{tabular}

Fuente: elaboración propia.

En particular, cuando analizamos la valoración de las noticias para la imagen de México por áreas temáticas encontramos que es negativa para la dimensión de política nacional con el porcentaje de 39,4\%; y positiva para la política exterior con resultados de 6,6 \%, para economía 9,8 \% y cultura un $10,8 \%$.

En consecuencia, la imagen negativa se da porque aparece informativamente como un país peligroso, vinculado a la violencia e inseguridad. Además, se presenta como un Gobierno frágil para atajar la violencia, consolidar el respeto a los derechos humanos de activistas, periodistas y mujeres y combatir la corrupción. En contraste, la imagen económica es positiva porque recibe un tratamiento como país seguro para invertir, estable económicamente y con perspectivas de crecimiento. Algo semejante ocurre con la dimensión cultural, la prensa transmite una idea de potencia cultural, la cual se respalda en el reconocimiento de sus cineastas y escritores.

De igual modo, la figura de política exterior es positiva; por un lado, se proyecta un país con un Gobierno y diplomacia combativa frente a los Estados Unidos y refrenda la concepción histórica de continuar siendo un país de asilo. Destaca la valoración negativa desde los medios para la relación con España, a raíz de la carta que envió el presidente mexicano al rey Felipe VI para exigir una disculpa de la Corona por los abusos cometidos contra los indígenas durante la Conquista. 
Por otro lado, las referencias negativas, equivalentes al 4,1\%, se dirigen principalmente para la gestión política que se ha hecho de la caravana migrante.

Llegados a este punto, por cada uno de los diarios, se tiene que en El País $(28,1 \%)$ y El Mundo $(8,7 \%)$ las valoraciones negativas tienen más peso cuantitativo que las valoraciones positivas (17,6 \% y 6,5 \%, respectivamente). En cuanto a La Vanguardia son más las noticias con valores favorables $(11,6 \%)$ que desfavorables $(10,8 \%)$.

Ahora bien, las valoraciones neutrales, que se caracterizan como noticias en donde no hay clara una evaluación, presentan datos similares en los tres diarios: La Vanguardia muestra el 5,6 \%, El País arroja el $6 \%$ y El Mundo indica el 5,1\%.

Tabla 8

Valoración de la imagen de México por diarios

\begin{tabular}{|l|c|c|c|c|}
\hline \multicolumn{1}{|c|}{ Dimensión } & Positiva & Neutra & Negativa & Total \\
\hline La Vanguardia & $11,6 \%$ & $5,6 \%$ & $10,8 \%$ & $28,2 \%$ \\
\hline EI País & $17,6 \%$ & $6 \%$ & $28,1 \%$ & $51,6 \%$ \\
\hline EI Mundo & $6,5 \%$ & $5,1 \%$ & $8,7 \%$ & $20,2 \%$ \\
\hline TOTAL & $35,8 \%$ & $16,7 \%$ & $47,5 \%$ & $100 \%$ \\
\hline
\end{tabular}

Fuente: elaboración propia.

\section{CONCLUSIONES}

Los resultados de esta investigación permiten llevar a cabo las siguientes conclusiones sobre la cobertura de México en tres diarios españoles de influencia internacional. En primer lugar, la producción noticiosa sobre México la concentra El País. De cada diez noticias, cinco son las publicadas en este medio; en contraste, de cada diez, tres aparecen en La Vanguardia y dos más en El Mundo. Este hecho revela la gran influencia e impacto del periódico El País a nivel internacional -sobre todo en el mundo donde se habla español- para transmitir imágenes, ideas y percepciones de México. En segundo lugar, las variaciones mensuales en la cobertura son de normalidad informativa; esto es, cuando hay asuntos de interés aumenta la publicación de noticias, cuando baja su importancia, tienen menos atención periodística. Además, pone de relieve lo señalado por (Cohen, 1963; McCombs y Shaw, 1972) en relación con los medios de comunicación que: "establecen no qué ni cómo la gente debe pensar, sino aquellos temas en torno a los cuales pensar, discutir y formarse una opinión"

En tercer lugar, y siguiendo a Ghanem (2009), con su propuesta de cuatro dimensiones de estudio para analizar los atributos y frames: 1.- El asunto de una noticia; 2.- La presentación (tamaño y ubicación); 3.- Los atributos cognitivos (detalles de aquello que es incluido en el frame); y 4.- Los atributos afectivos (los matices), podemos concluir que la relevancia informativa de las noticias analizadas en esta investigación es de nivel medio; es decir, el 46,3 $\%$, del total de informaciones que se publican, ocupan dos cuartos de página, una foto y alguno de los siguientes elementos: una ilustración o esquema. En cuarto lugar, la Ciudad de México, con el $70 \%$, es el principal epicentro donde se originan los acontecimientos que cubren los periodistas. Este dato nos lleva a afirmar que la cobertura se configuró en términos de Estado 
centralista, donde primaron las informaciones que ocurrieron en la capital del país, territorio que concentra el poder político, económico y cultural.

En quinto lugar, destacan y priman los temas de política nacional (violencia, Gobierno de AMLO, corrupción) sobre los de política exterior (relación con Estados Unidos, España), así como de cultura (cine y literatura) y económicos-negocios (inversiones en México). La agenda informativa es muy homogénea y de escasa diversidad por parte de los tres diarios; este hecho demuestra que el tipo de atributos que forman parte de esta construcción informativa han buscado "definir un tema o idea central" (McCombs y Ghanem, 2001), procurando encuadrar en los imaginarios sociales receptores a los asuntos políticos que generan mayor interés periodístico por su naturaleza de enfrentamiento entre los diversos actores y pueden atraer a un mayor número de lectores.

En sexto lugar, los políticos (presidente, funcionarios del Gobierno y miembros de los partidos políticos) son los personajes relevantes en el mayor número de noticias. Con ello, se sigue el mismo patrón que presenta el predominio de los asuntos de política nacional que condiciona que las informaciones estén protagonizadas principalmente por los actores políticos.

En séptimo lugar, las cifras globales de la valoración integral de las noticias para la imagen de México son más negativas que positivas. Distribuida de la siguiente manera, en cuatro espacios: primero, desfavorable para la dimensión de política interna, que supone la mitad de las noticias sobre el país en los diarios españoles; luego, favorable para tres ámbitos, como son el de cultura, economía y política exterior.

Estos resultados muestran que predomina una imagen país desfavorable, en términos totales; como consecuencia forjada por la cobertura y tratamiento de las noticias políticas que monopolizan la agenda periodística. Pero cuando el análisis se realizó por áreas, observamos que la política exterior, cultura y economía, puntuadas con valores positivos, tienen un efecto importante para matizar la imagen internacional negativa del país que se proyecta desde la prensa.

En términos generales, el análisis de los datos obtenidos pone de manifiesto un interés informativo medio de México por parte de los diarios La Vanguardia, El País y El Mundo; una de las razones por las cuales la cobertura de las noticias parece coincidir con los estudios de la agenda setting, que señalan que la imagen país puede verse afectada en función del tratamiento de las noticias que se publican de una nación y que condicionan su percepción exterior.

De manera particular, los resultados de este trabajo permiten profundizar en la producción de conocimiento científico entre prensa internacional e imagen país y en su relación de cómo se define la imagen de México en España, porque la información periodística es uno de los elementos esenciales para construir realidades y significados sociales (Berger y Luckmann, 1968; Casero, 2009). Además, la reputación de un país puede ser entendida como aquella representación colectiva que provoca una mayor o menor confianza en las expectativas de futuro de sus audiencias (Fombrum, 2001; Villafañe, 2004; Manfredi, 2013); conjuntamente, aporta el desarrollo de un enfoque teórico fundamentado en la teoría de la agenda setting y una metodología basada en el análisis de contenido para abordar el estudio de la representación exterior de un país determinado. 
Así, partiendo de esta base, se pueden plantear diversas vías de investigación que en un futuro sirvan para ampliar y completar los resultados mostrados en este artículo: ampliando la muestra cronológica o de medios. De igual manera, conviene señalar que la creación de una Secretaría de Estado en México que atienda temas relacionados con la agenda setting y marca-país, similar a la Secretaría de Estado de la España Global, creada en octubre de 2018 por el gobierno de Pedro Sánchez (Real Decreto 1266/2018, de 8 de octubre), pudiera desencadenar distintas líneas de actuación que contribuyan a la obtención de objetivos económicos, políticos y sociales. Tales como, atracción de turistas, inversores, aumento de exportaciones o mayor influencia política de México en otros países.

Quedan abiertas no pocas posibilidades de completar este trabajo. Pero quizá sean precisamente todas esas posibilidades una de las principales carencias de la investigación y, a la vez, una de sus más claras aportaciones.

\section{Referencias}

Acosta, M. (2006). La prensa de referencia mexicana y el discurso del Mercosur [Tesis Maestría en Comunicación, Universidad Iberoamericana]. http://ri.ibero.mx/handle/ibero/685?show=full

Aruguete, N. (2009). Estableciendo la agenda. Los orígenes y la evolución de la teoría de la Agenda Setting. Ecos de la Comunicación, 2(2), 11-38. https://repositorio.uca.edu.ar/handle/123456789/7119

Asociación para la Investigación de Medios de Comunicación (AIMC) (2019). Estudio general de medios. http://aimc.es. (Fecha de consulta 23 de febrero de 2020).

Antovica, A., de Esteban Curiel, J., y Gértudix Barrio, M. (2014). La comunicación entre España y los países bálticos a través de la prensa escrita española. Estudios sobre el mensaje periodístico. Volumen 20, Número 1. Pp. 297-312. http://dx.doi.org/10.5209/rev_ESMP.2014.v20.n1.45233

Azpiroz, M. L. (2013). Diplomacia pública. El caso de "la Guerra contra el terror". Universitat Oberta de Catalunya.

Bartolezzi, L. (1974). El ecosistema informativo (Introducción al estudio de las noticias internacionales). Ediciones Universidad de Navarra.

Curzio, L. (2017). Orgullo y prejuicios. Reputación e imagen de México. Porrúa.

Dearing, J. y Elder, C. (1992). Concepts: agenda-setting. Thousand Oaks. Sage.

El País. (2019). El País refuerza su apuesta por América. https://bit.ly/3FBSBQk

Gabino, M. (2012). La imagen de México. ¿Una representación partidista? Análisis a través de El País y EI Mundo. En C. Mateos Martín (Ed), Actas IV Congreso Internacional Latina de Comunicación (pp. 1-8). Universidad de La Laguna. http://www.revistalatinacs.org/12SLCS/2012_actas.html

González, C., Martínez, P. y Sánchez, J. A. (2020). La presencia de España en la prensa internacional ¿De qué se habla cuando se habla sobre España? [Documentos de Trabajo 2/2020, Real Instituto Elcano]. https://bit.ly/3v30iu3

Hoffman, D. (2002). Beyond Public. Diplomacy. Foreign Affairs. Volumen 81, número 2, marzo-abril, p. 8395. https://www.nato.int/structur/library/bibref/public_diplomacy.pdf

Igartua, J. J. (2006). Métodos cuantitativos de investigación en comunicación. Bosch.

Dinnie, K. (2008). Nation Branding: Concepts, Issues, Practice. Routledge

Del Orbe Ayala, K. R. (2018). México, en la prensa catalana. Reseña libro. Razón y Palabra. Número 22 (2, 101), Pp. 713-715. https://revistarazonypalabra.org/index.php/ryp/article/view/1217

Krippendorf, K. (1990). Metodología de análisis de contenido. Paidós.

McCombs, M.y Shaw, D. (1972). The agenda-setting function of mass media. Public Opinion Quarterly, Vol. (36) (82), Pp. 176-187. http://dx.doi.org/10.1086/267990 
McCombs, M. (2005). A look of Agenda-setting: past, present and future. Journalism Studies, Vol. (6) (4), pp. 543-557.

McCombs, M. (2006). Estableciendo la agenda. El impacto de los medios de la opinión pública y el conocimiento. Paidós.

Miranda, O. e Iglesias, A. (2015). Agenda-Setting de Medios en la Guerra contra las drogas. Estudios sobre el Mensaje Periodístico. Vol. (21) No. (1), pp. 403-420. https://revistas.ucm.es/index.php/ESMP/article/view/49102

Neuman, J. (1996). The Media's Impact on International Affairs, Then and Now. The Johns Hopkins University Press. Vol. (16) (1), pp. 109-123. https://muse.jhu.edu/article/30298

Nieto, A. y Peña, M. (2008). La diplomacia pública: los medios informativos como instrumento de política exterior. Revista Estudios Políticos. Número (13-15), ene./dic., pp. 149-164. http://dx.doi.org/10.22201/fcpys.24484903e.2008.0.18763

Noya, J. (2007). Diplomacia pública para el siglo XXI. Real Instituto Elcano.

Observatorio de México en España (ObsMex) (2019). https://www.obsmex.com/libros-y-publicaciones

Sádaba Garraza, M. T. (2001). Origen, aplicación y límites de la «teoría del encuadre» (framing) en comunicación. Comunicación y Sociedad, Vol. (XIV) (2), pp. 143-175. https://dadun.unav.edu/handle/10171/7975

Santillán, J. R. y Del Orbe, K. (2020). Cineastas mexicanos y poder suave. Una mirada desde la prensa española. En Larrondo, A. Y Meso, K (Ed.), Periodismo Hiperconectado. Claves para la profesión en un contexto de retos y oportunidades (pp. 81-92). Sociedad Española de Periodística.

Santillán, J. R. (2018). Visiones de México España. Artículos sobre imagen país, poder cultural e inmigración. Círculo Rojo.

Santillán, J. R. (2017). México, en la prensa catalana. Análisis en La Vanguardia y El Periódico de Catalunya. Sociedad Latina de Comunicación Social.

Santillán, J. R. y Acosta, M. (2019). El sexenio de Enrique Peña Nieto en la prensa española: El Mundo y la Vanguardia [Informe de Investigación No. 1., Observatorio de México en España]. https://bit.ly/3Dw4eHO

Saperas, E. (1987). Los efectos cognitivos de la comunicación. Ariel.

Sotos, E. y Sánchez, J. A. (2016). La imagen de España en la prensa internacional: segundo semestre [Cuaderno de Trabajo 8., Real Instituto Elcano]. https://bit.ly/3Bu1aKB

Shütz, A. (1995). El problema de la realidad social. Amorrortu.

Schütz, A. y Luckmann, T. (2003). Las estructuras del mundo de la vida. Amorrortu.

Tulloch, C. (2004). Corresponsales en el extranjero. Mito o realidad. Eunesa Ediciones de la Universidad de Navarra.

Urdaneta, M. (2011). La imagen de Venezuela en la prensa española. Una visión desde los diarios: El País, El Mundo, ABC y La Vanguardia. Revista Mediterránea de Comunicación, Vol. (2) Año (1). Pp. 1542. https://doi.org/10.14198/MEDCOM2011.2.02

Urriza, F. (2012). Construcción periodística de México en España: El País y ABC [Tesis de Fin de Máster, Universidad de Sevilla]. https://hdl.handle.net/11441/98579

Vidal, B. y Imbert, G. (1986). El País o la referencia dominante. Mitre.

Villanueva, C. (2012). Imagen país y política exterior de México. Revista Mexicana de Política Exterior, no. 96 (octubre), pp. 13-43. https://bit.ly/3an6cNa

Wimmer, R. y Dominick, J. (1997). La investigación científica de los medios de comunicación. Una introducción a sus métodos. Bosch.

Xifra, J. y San Eugenio, J. (2014). Representación internacional estrategias para naciones sin estado. El Caso de Cataluña y su diplomacia cultural. Place Branding and Diplomacy Public, Vol. (11), (1), 
83-96.

\section{Semblanza de los autores}

José Ramón Santillán Buelna es Doctor en Ciencia Política y Máster en Teoría Política y Social por la Universidad Pompeu Fabra. Licenciado en Periodismo por la Universidad Iberoamericana. De 2006 a 2017 ha sido profesor titular (i) en la Universidad Rey Juan Carlos. También ha enseñado en la Universidad Iberoamericana y el Tecnológico de MonterreyToluca. Especialista en comunicación política, en métodos de investigación y en la inmigración mexicana en España. Es autor de tres libros: Visiones de México en España (2018); México, en la prensa catalana (2017); La prensa mexicana frente al cambio político (2009). Además de 20 artículos científicos sobre elecciones, periodismo, opinión pública, migración mexicana y medios de comunicación. Actualmente es investigador en el Grupo de Estudios Avanzados en Comunicación (www.geac.es) y desde 2018 dirige el Observatorio de México en España, centro de investigación, con sede en Barcelona, que estudia la imagen país, la proyección del poder suave y a la migración mexicana en España.

Alberto Zuart Garduño es politólogo internacional, Doctor Cum Laude en Política y Gobierno por la Universidad Complutense de Madrid. Miembro de la Asociación Iberoamericana de Investigación en Sociología de las Organizaciones y la Comunicación, Evaluador Acreditado de políticas públicas del Gobierno de México, Investigador Asociado del Observatorio de México en España, así como Colaborador habitual de la Fundación Internacional para el Desarrollo de Gobiernos Confiables y del Instituto Nacional Electoral de México. Ha sido investigador y profesor visitante en diferentes universidades europeas, latinoamericanas y norteamericanas. Ha publicado ¿Adiós democracia de partidos?, Gobernabilidad Democrática y Derechos Fundamentales, Escenarios sobre violencia, comunicación y organizaciones. Una discusión abierta en el contexto Iberoamericano, México, una democracia en crisis de confianza y satisfacción, años 2000 - 2018, Formación y desarrollo de los partidos políticos tradicionales en México. Una aproximación crítica, entre otros. Sus líneas de trabajo investigación y docencia prioritarias son: democracia, comunicación política, opinión pública y parlamento. 